Article

\title{
An Algorithm for Individual Dosage in Cadmium-Zinc-Telluride SPECT-Gated Radionuclide Angiography
}

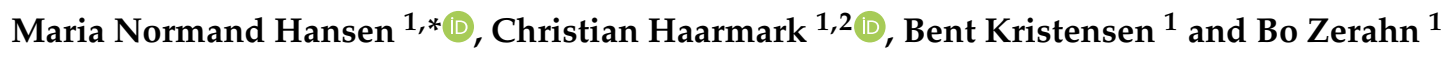 \\ 1 Department of Nuclear Medicine, Copenhagen University Hospital Herlev and Gentofte, \\ 2730 Herlev, Denmark; christian.eickhoff.haarmark.nielsen.01@regionh.dk (C.H.); \\ bent.kristensen.01@regionh.dk (B.K.); Bo.Zerahn@regionh.dk (B.Z.) \\ 2 Department of Clinical Medicine, University of Copenhagen, 2200 Copenhagen, Denmark \\ * Correspondence: marianormand@outlook.dk
}

Citation: Hansen, M.N.; Haarmark, C.; Kristensen, B.; Zerahn, B. An Algorithm for Individual Dosage in Cadmium-Zinc-Telluride SPECT-Gated Radionuclide Angiography. Diagnostics 2021, 11, 2268. https://doi.org/10.3390/ diagnostics11122268

Academic Editors: Albert Comelli, Cecilia Di Ruberto,

Alessandro Stefano, Lorenzo Putzu and Andrea Loddo

Received: 14 October 2021

Accepted: 2 December 2021

Published: 4 December 2021

Publisher's Note: MDPI stays neutral with regard to jurisdictional claims in published maps and institutional affiliations.

Copyright: (C) 2021 by the authors. Licensee MDPI, Basel, Switzerland. This article is an open access article distributed under the terms and conditions of the Creative Commons Attribution (CC BY) license (https:// creativecommons.org/licenses/by/ $4.0 /)$.

\begin{abstract}
The aim of the present study was to test an individualised dose without compromising the ease of analysing data when performing equilibrium radionuclide angiography (ERNA) using cadmium-zinc-telluride (CZT) SPECT. From March 2018 to January 2019, 1650 patients referred for ERNA received either an individualised dose of ${ }^{99 m}$ Tc-labeled human serum albumin (HSA) according to their age, sex, height, and weight $(n=1567)$, or a standard dose of $550 \mathrm{MBq}(n=83)$. The target count rate $\left(\mathrm{CR}_{\mathrm{T}}\right)$ was reduced every two months from 2.7 to $1.0 \mathrm{kcps}$. A final test with a $\mathrm{CR}_{\mathrm{T}}$ of $1.7 \mathrm{kcps}$ was run for three months to test whether an agreement within $2 \%$ points for the determination of LVEF, on the basis of only two analyses, was obtainable in at least $95 \%$ of acquisitions. All the included ERNAs were performed on a dedicated cardiac CZT SPECT camera. When using the algorithm for an individualised dose, we found that agreement between the measured and predicted count rate was $80 \%$. With a $\mathrm{CR}_{\mathrm{T}}$ of $1.7 \mathrm{kcps}$, the need for more than two analyses to obtain sufficient agreement for LVEF was $4.9 \%$. Furthermore, this resulted in a mean dose reduction from 550 to 258 MBq. Patients' weight, height, sex, and age can, therefore, be used for individualising a tracer dose while reducing the mean dose.
\end{abstract}

Keywords: personalised medicine; RNA; CZT SPECT; gated SPECT

\section{Introduction}

Technological advances in cancer treatment and screening procedures have resulted in an increase in long-term cancer survivors [1-3]. This has led to an increased need for managing the potential long-term side effects of chemotherapy and radiotherapy, among which, cardiovascular complications are frequent $[2,3]$. Therefore, accurate monitoring of cardiac function during potentially cardiotoxic chemotherapy is of importance. Patients undergoing potentially cardiotoxic chemotherapy are often monitored by quantifying left ventricular ejection fraction (LVEF). Several consecutive measurements are used when monitoring for cardiotoxic effects and for subsequent therapeutic decisions.

Chemotherapy-induced cardiac damage may be caused by a direct toxic effect or as an accelerated development of cardiovascular disease and appears up to years after the initiation of treatment [4,5].

Several techniques are currently available for this monitoring of LVEF [3,6]. Equilibrium radionuclide angiography (ERNA) is a well-validated non-invasive test [7], and in particular, cadmium-zinc-telluride single-photon emission tomography (CZT SPECT) radionuclide angiography ranks high, due to practicability, operator independency, and reproducibility [8-10].

Since radionuclide angiography was implemented for clinical use in the 1980s, development has moved toward shorter acquisition times and lower doses of tracer. In 2016, Duvall et al. reported that an injected dose of tracer may be reduced by up to $50 \%$ without compromising the image quality [9]. The new dedicated cardiac cameras with CZT 
detectors and individualising the activity administered to each patient should, therefore, enable a reduction in radiation exposure even further [8-15].

Previous studies have already evaluated the possibility of using personalised models when planning doses for a radionuclide-based assessment of cardiac function. These studies have primarily focused on myocardial perfusion imaging [11-13,16,17], but one study has evaluated planar ERNA where the dose was based upon the patient's physical variables according to a chart and not a formula, which was declared to be a weakness of the method [18].

When performing CZT SPECT-gated radionuclide angiography, it has previously been shown that the patients' height, weight, sex, and age may explain up to $75 \%$ of the variation in the count rate $[19,20]$. The next step, as suggested in an editorial by Joris D. van Dijk [21], is to test this information in a clinical setting. Subsequently, the aim of this study was to test dose planning in an everyday setting $[19,20]$ with the goal of reducing radiation exposure without compromising the ease of processing data.

\section{Materials and Methods}

\subsection{Population}

From March 2018 to January 2019, a total of 1696 patients were referred for routine assessments of LVEF. Patients received either an individualised dose according to their weight, height, sex, and age, or a standard dosage of $550 \mathrm{MBq}$ if data on weight and height were insufficient upon referral. Patient flow is illustrated in Figure 1, and detailed information on target count rate groups is shown in Table 1.

Table 1. Detailed information on patient flow with regard to target count rate and cameras used for ERNA.

\begin{tabular}{|c|c|c|c|c|c|c|}
\hline Target Count Rate (cps) & 1.0 & 1.5 & 1.7 & 2.0 & 2.7 & Total \\
\hline Equations used & 1 and 2 & 1 and 2 & 1 and 2 & 1 and 2 & 1 & \\
\hline Patients referred for ERNA & 328 & 303 & 444 & 323 & 298 & 1696 \\
\hline Injection of FDG prior to ERNA & 0 & 0 & 0 & 0 & 1 & 1 \\
\hline NaI SPECT & 4 & 0 & 2 & 2 & 1 & 9 \\
\hline NaI planar & 4 & 6 & 5 & 3 & 0 & 18 * \\
\hline Dose other than scheduled & 2 & 5 & 3 & 3 & 5 & $18^{* *}$ \\
\hline $\begin{array}{l}550 \mathrm{MBq} \text { due to missing data on } \\
\text { height and weight }\end{array}$ & 4 & 6 & 2 & 30 & 41 & 83 \\
\hline $\begin{array}{c}\text { Received scheduled dose and } \\
\text { CZT ERNA }\end{array}$ & 314 & 286 & 432 & 285 & 250 & 1567 \\
\hline Minimum dose of $150 \mathrm{MBq}$ & 0 & 15 & 0 & 1 & 19 & 35 \\
\hline Minimum dose of $100 \mathrm{MBq}$ & 36 & 0 & 0 & 0 & 0 & 36 \\
\hline
\end{tabular}

* Fourteen because of inability to raise left arm, one had to be seated upright because of dyspnoea, two were claustrophobic, and one because of sternectomy causing edge detection algorithms for SPECT to fail. ** Ten were given an extra dose of tracer due to suspicion of a partially paravenous administration of tracer due to far lower count rates than expected, five cases were due to visual suspicion of a paravenous tracer injection, one case was due to the tracer being spilt, one case was due to an obvious mismatch between information on height and weight and patient appearance, and one case was due to the patient arriving $3 \mathrm{~h}$ later than scheduled.

Sex, age, blood pressure, heart rate, body weight, and body height were registered, and information on anthropometric data, cardiac variables, dosage information, and frequency of need for more than two analyses is provided in Table 2. The study was conducted according to the guidelines of the Declaration of Helsinki and approved by the Institutional Review Board (Herlev Gentofte Hospital Directional Board, 26 February 2021, WorkZone number: 20076870). 


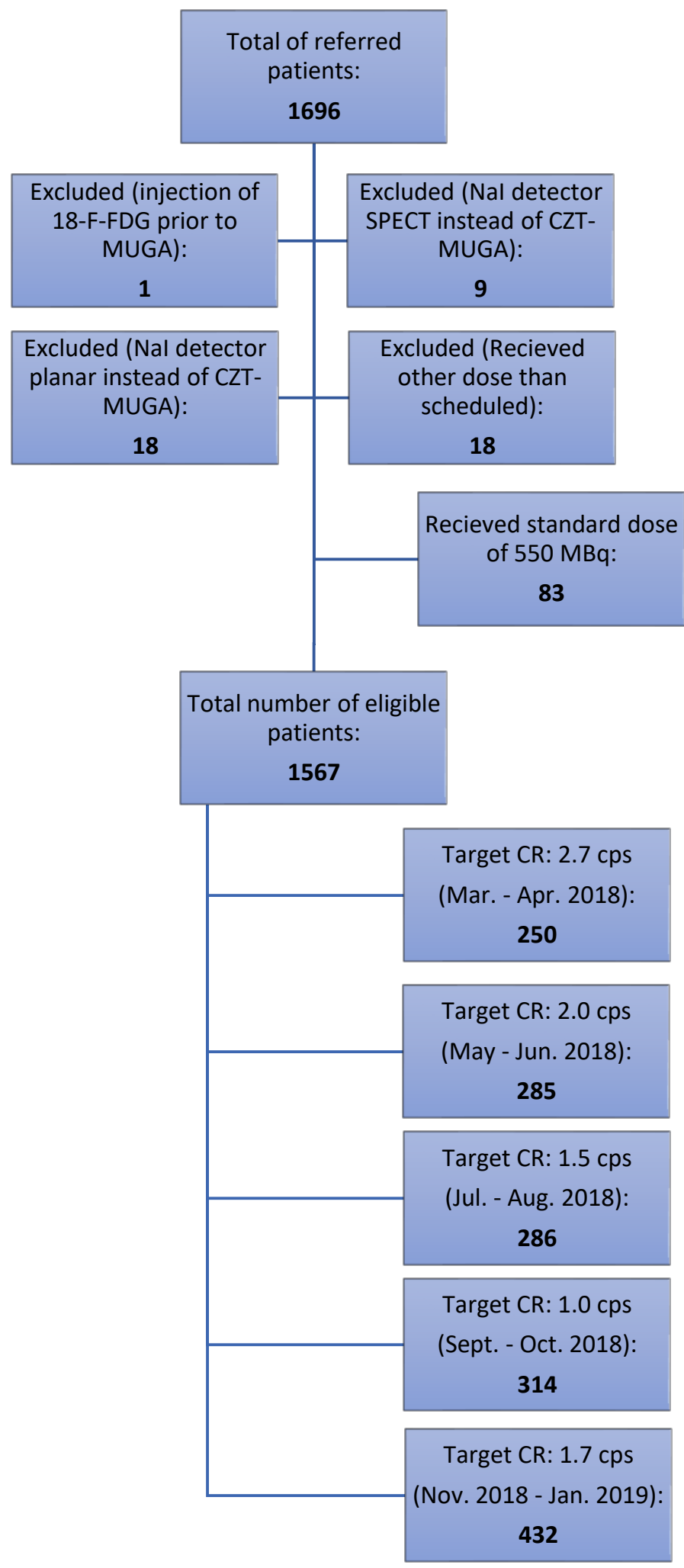

Figure 1. Flow chart of patients in and excluded from the study. 
Table 2. Anthropometric data, cardiac variables, dosage information, and frequency of need for more than two analyses depending on target count rate.

\begin{tabular}{|c|c|c|c|c|c|c|c|c|c|c|c|c|c|c|c|c|c|c|c|c|c|c|}
\hline & \multirow{3}{*}{$\begin{array}{c}\text { Target Count Rate Group } \\
\text { Time Period } \\
n \text { (Female } / \%)^{*}\end{array}$} & \multicolumn{3}{|c|}{1.0} & \multicolumn{3}{|c|}{1.5} & \multicolumn{3}{|c|}{1.7} & \multicolumn{3}{|c|}{2.0} & \multicolumn{3}{|c|}{2.7} & \multicolumn{3}{|c|}{$\begin{array}{l}\text { Standard Dose } \\
\text { (550 MBq) }\end{array}$} & \multicolumn{3}{|c|}{ All } \\
\hline & & \multicolumn{3}{|c|}{ Sep-Oct 2018} & \multicolumn{3}{|c|}{ Jul-Aug 2018} & \multicolumn{3}{|c|}{ Nov 2018-Jan 2019} & \multicolumn{3}{|c|}{ May-Jun 2018} & \multicolumn{3}{|c|}{ Mar-Apr 2018} & \multicolumn{3}{|c|}{ Mar 2018-Jan 2019} & \multicolumn{3}{|c|}{ Mar 2018-Jan 2019} \\
\hline & & 314 & 215 & $68.5 \%$ & 286 & 190 & $66.4 \%$ & 432 & 301 & $69.7 \%$ & 285 & 187 & $65.6 \%$ & 250 & 163 & $65.2 \%$ & 83 & 54 & $65.1 \%$ & 1650 & 1110 & $67.3 \%$ \\
\hline Row & Variable & Mean & SD & SEE & Mean & SD & SEE & Mean & SD & SEE & Mean & SD & SEE & Mean & SD & SEE & Mean & SD & SEE & Mean & SD & SEE \\
\hline 1 & Age (years) * & 59.6 & 15.1 & 0.9 & 61.0 & 14.5 & 0.9 & 61.0 & 14.2 & 0.9 & 60.6 & 14.8 & 0.9 & 61.4 & 13.9 & 0.9 & 61.2 & 14.3 & 1.6 & 60.7 & 14.5 & 0.4 \\
\hline 2 & Height $(\mathrm{cm})$ * & 168.9 & 8.9 & 0.5 & 169.2 & 8.6 & 0.5 & 168.5 & 8.7 & 0.4 & 169.5 & 8.6 & 0.5 & 169.2 & 8.9 & 0.6 & 170.0 & 9.2 & 1.0 & 169.0 & 8.8 & 0.2 \\
\hline 3 & Weight $(\mathrm{cm}) *$ & 74.8 & 16.0 & 0.9 & 74.7 & 16.8 & 1.0 & 73.5 & 14.9 & 0.7 & 75.7 & 16.6 & 1.0 & 75.1 & 17.2 & 1.1 & 74.3 & 14.9 & 1.6 & 74.6 & 16.1 & 0.4 \\
\hline 4 & Heart rate $\left(\mathrm{s}^{-1}\right)^{*}$ & 73.2 & 13.5 & 0.8 & 73.3 & 14.0 & 0.8 & 73.9 & 13.1 & 0.8 & 73.4 & 13.1 & 0.8 & 72.9 & 12.4 & 0.8 & 71.9 & 12.9 & 1.4 & 73.3 & 13.4 & 0.3 \\
\hline 6 & Diastolic blood pressure $(\mathrm{mmHg}) *$ & 73.8 & 10.4 & 0.6 & 74.0 & 9.6 & 0.6 & 75.6 & 10.3 & 0.5 & 73.7 & 10.4 & 0.6 & 74.2 & 10.6 & 0.7 & 75.0 & 9.2 & 1.0 & 74.4 & 10.3 & 0.3 \\
\hline 7 & End diastolic volume $(\mathrm{mL}) * *$ & 88.2 & 25.9 & 1.5 & 90.3 & 25.2 & 1.5 & 88.8 & 26.1 & 1.3 & 92.0 & 25.1 & 1.5 & 93.1 & 25.7 & 1.6 & 96.5 & 28.3 & 3.1 & 90.6 & 25.8 & 0.6 \\
\hline 8 & End systolic volume $(\mathrm{mL}) * *$ & 30.9 & 17.4 & 1.0 & 32.0 & 15.9 & 0.9 & 32.5 & 16.8 & 0.8 & 34.2 & 15.5 & 0.9 & 34.9 & 17.8 & 1.1 & 33.9 & 18.9 & 2.1 & 32.8 & 16.8 & 0.4 \\
\hline 9 & LVEF $(\%)^{* *}$ & 66.5 & 11.8 & 0.7 & 65.8 & 10.7 & 0.6 & 64.8 & 11.4 & 0.6 & 63.9 & 10.9 & 0.6 & 64.0 & 11.5 & 0.7 & 66.9 & 12.8 & 1.4 & 65.1 & 11.4 & 0.3 \\
\hline 10 & Target dose $(\mathrm{MBq})$ & 182.6 & 91.2 & 5.0 & 249.4 & 103.2 & 6.1 & 258.1 & 93.0 & 4.5 & 309.8 & 107.0 & 6.3 & 371.4 & 140.0 & 8.8 & 536.2 & 24.9 & 2.7 & 282.3 & 132.1 & 3.3 \\
\hline 11 & $\begin{array}{l}\text { Dose adjusted for time of injection } \\
\qquad(\mathrm{MBq})\end{array}$ & 182.4 & 91.0 & 5.1 & 250.2 & 105.2 & 6.2 & 257.9 & 93.5 & 4.5 & 308.7 & 107.0 & 6.3 & 370.8 & 139.4 & 8.8 & 532.7 & 32.0 & 3.5 & 281.9 & 132.0 & 3.3 \\
\hline 12 & $\begin{array}{l}\text { Predicted count rate adjusted for } \\
\text { time of injection }\left(\mathrm{s}^{-1}\right)\end{array}$ & 1.20 & 0.26 & 0.01 & 1.68 & 0.24 & 0.01 & 1.78 & 0.23 & 0.01 & 2.07 & 0.26 & 0.02 & 2.49 & 0.49 & 0.03 & 4.00 & 1.01 & 0.11 & 1.92 & 0.72 & 0.02 \\
\hline 13 & Measured count rate $\left(\mathrm{s}^{-1}\right)$ & 1.20 & 0.33 & 0.02 & 1.64 & 0.39 & 0.02 & 1.84 & 0.42 & 0.02 & 2.13 & 0.41 & 0.02 & 2.60 & 0.68 & 0.04 & 4.01 & 1.16 & 0.13 & 1.96 & 0.82 & 0.02 \\
\hline
\end{tabular}

${ }^{*}$ No differences between groups; ${ }^{* *}$ no difference between groups after Bonferroni correction 
Anonymised data used in the current study are available from the corresponding author.

\subsection{Image Acquisition and Processing}

All the acquisitions were performed at the Department of Nuclear Medicine at HerlevGentofte Hospital. ERNAs were performed on a dedicated cardiac CZT SPECT gamma camera, GE Discovery 530c (GE Healthcare, Milwaukee, WI, USA). Each subject was either given an individualised dose (see below) of ${ }^{99} \mathrm{~m}$ Tc-labeled human serum albumin (HSA) intravenously on the basis of the algorithm below, or $550 \mathrm{MBq}$ if data on patient height and body weight were unavailable, as noted above. An acquisition protocol for multigated acquisition, using 16 bins per R-R interval, requesting 600 accepted beats, and a $20 \%$ energy window centred on $140 \mathrm{keV}$, was carried out.

Count rate was read from the work screen during acquisition and calculated as the mean of three readings (one at the beginning, middle, and end).

For image analyses, we used a Xeleris 3 Imaging workstation reorientation software (GE Healthcare, Milwaukee, WI, USA, version no. 3.0562) and Cedars-Sinai QBS processing software (Cedars-Sinai, Los Angeles, CA, USA, revision 2009.0).

Each acquisition was analysed by two experienced technologists independently of one another, and mean values of the cardiac variables were calculated. If the calculated LVEF varied by more than 2 percentage points, further analyses were performed until a sufficient agreement was obtained. Depending on the workflow circumstances, subsequent analyses were performed either by one of the two first technologist, a third technologist, or if necessary a physician. Apart from LVEF, data on left ventricular end diastolic and systolic volumes (EDV and ESV, respectively) were also recorded. Tracer dose was registered, and an adjustment was performed for differences between the scheduled and actual time of injection to the nearest $5 \mathrm{~min}$.

\subsection{Optimum Target Count Rate Identification and Equation Selection}

The following two equations for calculating patient tailored dose of ${ }^{99} \mathrm{~m} \mathrm{Tc}-$ labeled HSA were developed $\left(D_{P}=\right.$ planned dose, $X_{W}=$ weight, $X_{H}=$ height, $X_{G}=$ sex, $X_{A}=$ age, $C R_{T}$ = target count rate):

Equation (1) [20]:

$$
\begin{gathered}
D_{P}=550 \mathrm{MBq}-\left(E X P \left(1.8-0.028 X_{W}+0.00005 X_{W}{ }^{2}+0.0087 X_{H}+0.06 X_{G}\right.\right. \\
\left.\left.-0.0021 X_{A}\right)-C R_{T}\right) / 0.00756
\end{gathered}
$$

Equation (2) [19]:

$$
D_{P}=550 \mathrm{MBq} \times C R_{T} / \operatorname{EX} P\left(1.621-0.020 X_{W}+0.008 X_{H}+0.06 X_{G}-0.002 X_{A}\right)
$$

Both equations were derived on the basis of previous examinations of a large patient group who all received a fixed dose of tracer (550 MBq ${ }^{99 \mathrm{~m}} \mathrm{Tc}-$ labeled HSA) $[19,20]$. The main difference between the two equations is the insertion of an extra element in equation 1 with body weight squared.

Equation (1) was tested on the first group of patients, aiming at a target count rate of $2.7 \mathrm{kcps}$ for a period of 2 months running through March and April 2018. However, this equation alone often suggests negative doses for patients with the lowest body weights, as illustrated in Figure 2, where the suggested patient doses for each equation is plotted against patient weight. In such cases, a minimum dose of $150 \mathrm{MBq}$ was used (see below). On the other hand, Equation (2) suggests high doses in patients with a high body weight (Figure 2). In the large group of patients with a more average body weight, there were only minor differences between the two equations with regard to the suggested dose. As a consequence, the two equations were combined in to one algorithm that was used from May 2018 onwards, using Equation (1) in patients with a body weight $\geq 73 \mathrm{~kg}$ and Equation (2) for those with a body weight $<73 \mathrm{~kg}$. 


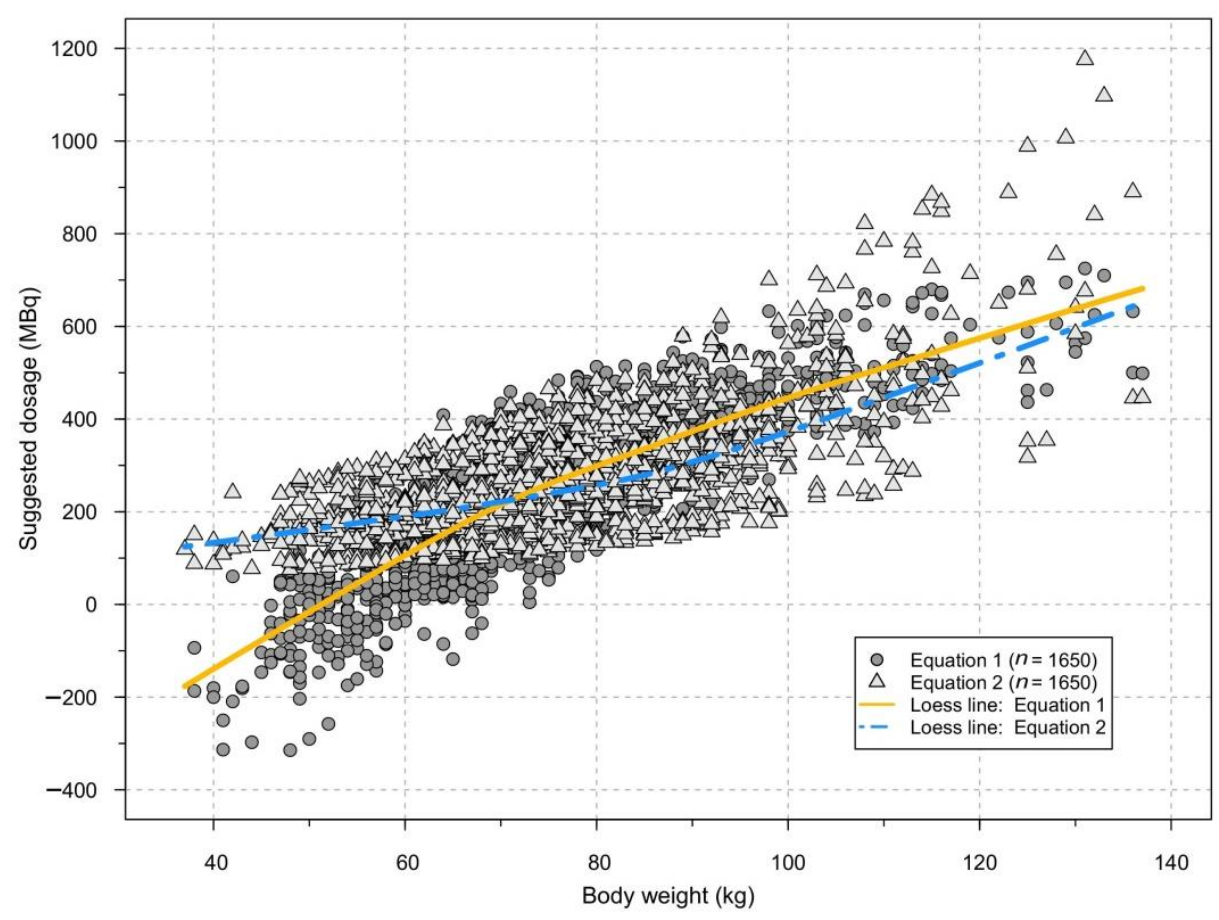

Figure 2. Suggested dosage plotted against weight, depending on equation used.

Different target count rates were each tested for two months at a time, moving gradually downwards from 2.7 to $1.0 \mathrm{kcps}$ (see Figure 1 and Table 2). This was performed in order to identify a level for the target count rate, where the frequency of two analyses of the same acquisition reaching an agreement of LVEF within 2 percent points was approximately $95 \%$. Hereafter, target count rate was set to $1.7 \mathrm{kcps}$ to test if this was appropriate to meet the requested frequency of sufficient agreement between analyses.

Patients were injected with a minimum dose of $150 \mathrm{MBq}$ when aiming at count rates of $2.7(19(7.6 \%))$ and $1.5 \mathrm{kcps}(15(5.2 \%))$, and $100 \mathrm{MBq}$ when aiming at a count rate of $1.0 \mathrm{kcps}$ $(36(11.5 \%))$ (Table 1$)$. This was in order to stay above the minimum activity recommended for children with a $20 \%$ safety margin according to EANM dose recommendations [7]-a necessary precaution to avoid low, and also occasionally negative, doses suggested when using Equation (1) alone (target count rate 2.7) and in order to avoid the need for frequent re-injections when aiming at count rates of 1.5 and $1.0 \mathrm{kcps}$. Accordingly, the need to use the minimum dose was $0(0 \%)$ and $1(0.004 \%)$ for target count rate groups 1.7 and 2.0 , respectively.

\subsection{Subgroup Analyses}

In 122 of the assessments (32 with target count rate of 1.0 kcps and 90 with target count rate $1.7 \mathrm{kcps}$ ), the remaining activity in needles and syringes was measured after injection of tracer in order to evaluate how much of the scheduled tracer activity was left in these utensils, in order to evaluate the subsequent potential influence on count rate.

\subsection{Statistical Analyses}

All statistical analyses were conducted with IBM Corp. Released 2017. IBM SPSS Statistics for Windows, Version 25.0. Armonk, NY, USA: IBM Corp.

Scatter plots were made in RStudio, RStudio Team (2019). RStudio: Integrated Development for R. RStudio, Inc., Boston, MA, USA, available on http:/ / www.rstudio.com/pr oducts/rstudio/download/\#download (accessed on 9 September 2020).

Group comparison was performed with ANOVA and Bonferroni correction for multiple comparisons and a $t$-test for comparisons between two groups. 
Linear regression analysis (Pearson correlation coefficient) was used to quantify the degree of association between measured and predicted count rate in all included patients.

Level of significance was set at a $5 \%$ level.

\section{Results}

\subsection{Population}

A total of 1567 patients received individualised activity protocol, and 83 received a standard activity of $550 \mathrm{MBq}$ due to insufficient data on their height and weight upon referral. In 27 cases, acquisitions were excluded because NaI detector SPECT or planar was performed instead, 18 cases were excluded if the patient received another dose than scheduled, and 1 case was excluded due to an injection of 18-F-FDG prior to ERNA.

The patients who received an individualised dose or standard dose $(n=1650)$ for ERNA received treatment for breast cancer, 697 (42.2\%); leukaemia, 24 (1.4\%); lymphoma, 245 (14.9\%); sarcoma, 225 (13.6\%); renal cancer, 108 (6.6\%); hepatocellular carcinoma, 47 (2.9\%); ovarian cancer, 53 (3.2\%); malignant melanoma, 174 (10.6\%); and other cancers or more than one type of cancer, $77(4.7 \%)$.

There were no significant differences with regard to sex frequency, age, height, weight, heart rate at rest, and blood pressure between the patients in the five different target group periods (Table 2, rows 1 to 6 ).

Although the analysis of variance (ANOVA) between the target group periods indicated significant differences for end diastolic volume (EDV) and LVEF $(p=0.028 *$ for EDV, $p=0.053$ for end systolic volume (ESV), $p=0.017 *$ for LVEF), there were no significant differences between group analyses after the Bonferroni correction, indicating the risk of a possible error due to multiple comparisons. Despite this, the apparently increasing volumes for both EDV and ESV with the increasing mean dose could indicate some degree of partial volume effect. Nevertheless, there is no similar indication of changes in LVEF with the changes in the target count rate (Table 2, rows 7 to 9).

\subsection{Test of Patient Tailored Algorithm}

When plotting all the measured count rates against the predicted count rates $(n=1650)$, we found an excellent prediction of the count rate, as illustrated in Figure 3. Linear regression showed a slope coefficient of 1.012 and an intercept of $0.007 \mathrm{kcps}$. The algorithm based on information on patient weight, height, sex, and age explained $80 \%\left(R^{2}=0.80\right)$ of the variation in the observed count rate, which is an improvement from the expected $75 \%$.

When using the combination of Equations (1) and (2) as described, we were able to obtain a mean predicted count rate very close to the measured count rate ( 0 to $4.4 \%)$ throughout the range of target count rates from 1.0 to $2.7 \mathrm{kcps}$ while reducing the mean dose as the target count rate was lowered (Table 2, rows 10 to 13).

The gradual reduction in the target count rate led to a frequency of disagreement of more than 2 percent points between the LVEF analyses of an ERNA above 5\% when aiming at count rates of 1.5 and $1.0 \mathrm{kcps}$. This led to the decision to run the final test period from November 2018 to the end of January 2019, aiming at a count rate of $1.7 \mathrm{kcps}$. With this target count rate, a sufficiently low frequency of disagreement between the two first analyses of LVEF was obtained (21 out of 432 or $4.9 \%$ ) (Table 2, row 14).

An individualised dose reduced the overall mean dose by 53\% (from 550 to $258 \mathrm{MBq}$ ) when aiming at a count rate of $1.7 \mathrm{kcps}$, as compared to our standard dose of $550 \mathrm{MBq}$ (Table 2, rows 10 and 11). 


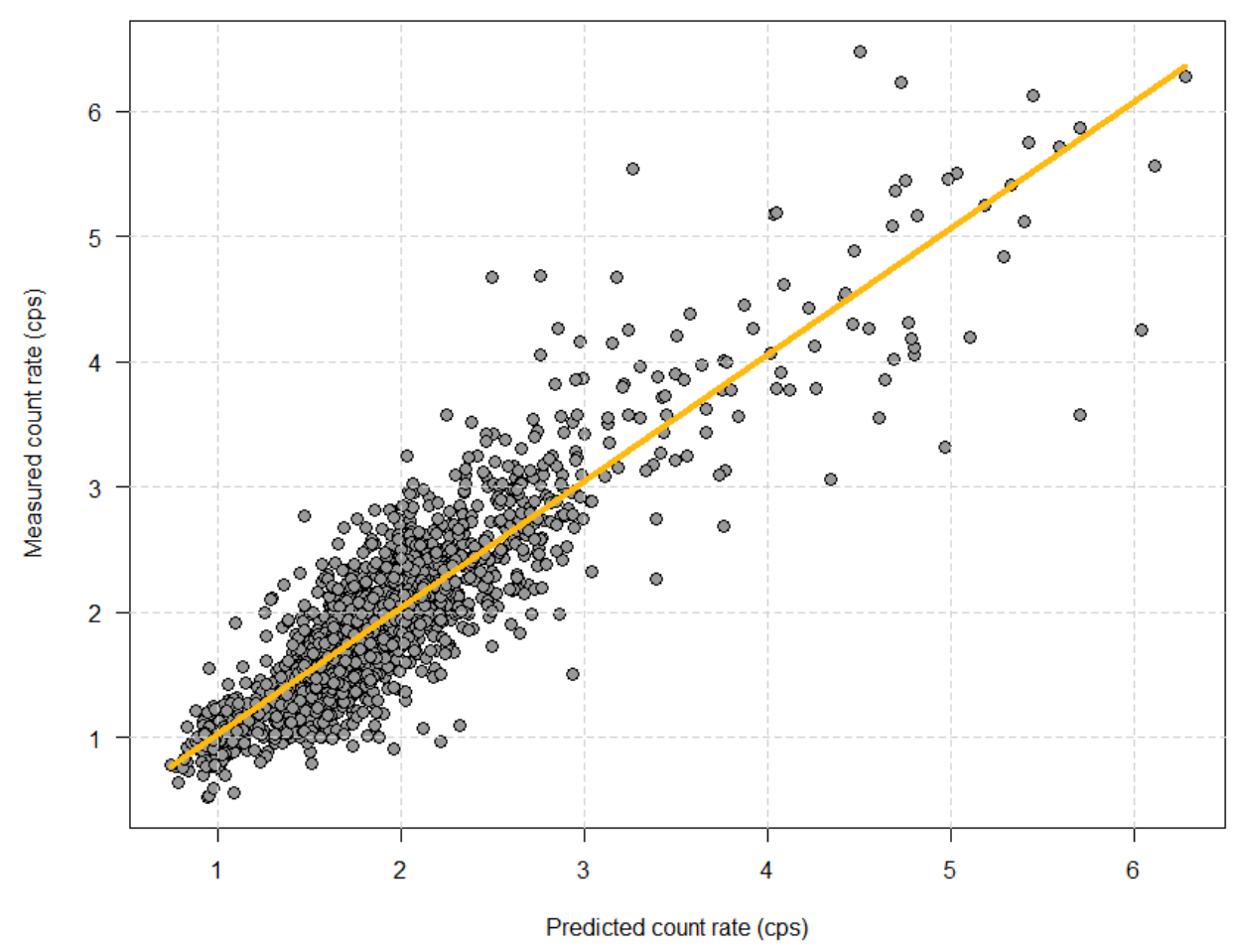

Figure 3. Predicted versus measured count rate.

The mean absolute (numerical) time between the scheduled and actual tracer injection was $9 \mathrm{~min}$, ranging from 0 to 140 . This gave rise to a mean absolute difference between the scheduled dose and the actual dose at injection of $5 \mathrm{MBq}(2 \%)$, ranging from 0 to $114 \mathrm{MBq}$, or up to $29 \%$.

\subsection{Subgroup Analyses}

In the injection utensils used for target count rates of 1.0 and $1.7 \mathrm{kcps}$, there was no difference in the remaining activity $(9.6 \pm 4.4$ vs. $10.4 \pm 5.4 \mathrm{MBq}$, respectively, $p=0.43$ for $t$-test with unequal variance). However, the relative remaining activity was higher in the utensils used for a target count rate of 1.0 than those used for a target count rate of $1.7 \mathrm{kcps}$ ( $5.5 \pm 3.1 \%$ vs. $4.3 \pm 2.7 \%$, respectively, $p=0.0083$ for $t$-test with unequal variance). The maximum remaining amount of tracer in the injection utensils was $16.5 \%$.

\section{Discussion}

This study successfully tested a combination of two equations for individualised dose planning in CZT ERNA, allowing for a reduction in the mean dose of at least 50\% (to a mean effective dose of $1.6 \mathrm{mSv}$ (range: 0.6 to $3.6 \mathrm{mSv}$ )), without compromising the ability to produce reproducible analyses of LVEF. The average dose using a target count rate of $1.7 \mathrm{kcps}$ is approximately half of the current recommendation for planar nuclear angiography [7,22], and as suggested possible by Duvall et al. [9].

Additionally, we found a level of the target count rate that minimises the need for a lower dose limit. When doing this, we used the frequency of disagreement of more than 2 percent points between the two LVEF calculations as a surrogate for image quality. Nonetheless, this limit is used in daily clinical practice and is subsequently practical in this context. While using the above-mentioned algorithms in daily practice, there were two instances in young males where the suggested dose was below the lower limit of $100 \mathrm{MBq}$ In response, we altered the weight limit used to decide which of the two equations to use from 73 to $82 \mathrm{~kg}$ (effectuated April 2020). This has been the only alteration that we have found it necessary to perform. 
There are several benefits to reducing the administered dose of radiopharmaceuticals. Primarily, optimising the exposure to radiation according to the "as low as reasonably achievable (ALARA) principles" would reduce the radiation burden to both patients and staff in accordance with both guidelines [23] and national legislation. Additionally, a more uniform count rate should improve the uniformity of test results, regardless of the patients' size, by eliminating the consequences of a partial volume effect caused by higher count rates in smaller patients versus lower count rates in patients with larger body proportions as well as the possibility to adapt the dose to the individual patient despite changes in body weight during therapy [24]. In the present study, however, this partial volume effect appears to be of minor importance since it has implications on EDV and ESV but not LVEF. As such, it is also unlikely that individualised tracer dosage has influenced the accuracy of the CZT SPECT ERNA procedure.

Administering an overall lower dose to each patient will inevitably reduce the costs of both the tracer and ${ }^{99 \mathrm{~m}} \mathrm{Tc}$ without altering the procedure, particularly with regard to scan time, although this doubles the need for more than two analyses to approximately $5 \%$. As an example, the number of vials per 100 performed ERNAs was, in our department, 39.8 in 2016, when the standard dose of $550 \mathrm{MBq}$ per acquisition was used, as compared to 27.3 in 2019, when a patient tailored dose aiming at a target count rate of $1.7 \mathrm{kcps}$ was used routinely, with an average cost reduction of $31.5 \%$. It is, however, mandatory that clinicians upon referral for ERNA provide sufficient information on weight and height for the computed calculation of an individual tracer dose. This has required some adaptation for the clinicians, which is reflected in Table 1, where the need for the use of the standard dose of $550 \mathrm{MBq}$ decreased from 41 and 30 in target count rate groups 2.7 and $2.0 \mathrm{kcps}$, respectively, to below 10 in the later series.

The individualised planning of doses and the on-the-fly monitoring of count rates makes it possible to pinpoint cases of a paravenous injection as the examination is running due to a lower count rate than expected. In this study, this happened in 10 out of 1650 cases.

There is an apparent improvement in the predictability of the count rate from the expected $75 \%$ as previously published to $80 \%$. This may well be attributed to the use of a combination of the two dose calculation equations instead of only using one, thus avoiding their respective weaknesses at each end of the spectrum of body weight (Figure 2). Another factor that may have marginally contributed is the adjustment for the exact tracer injection time instead of just using the scheduled time. Still, the mean deviation from the scheduled dose due to differences between the actual and planned injection time was only $4.3 \mathrm{MBq}(1.6 \%)$.

Variations due to unknown residual activity in injection utensils; differences in thorax shape; and the effect of varying tissue amounts around the heart due to prior surgery-left sided mastectomy, in particular-may account for other unexpected major deviations from the expected count rate [25]. It can be expected that the relative residue of tracer in injection utensils will increase with lower target doses as long as the same dilution of tracer is used.

\section{Conclusions}

Patients' weights, heights, sexes, and ages can be used to individualise the planning of their tracer doses using a combined algorithm with a target count rate. The benefits of this approach are numerous-most importantly, the radiation burden to both patients and staff can be reduced by at least 50\% compared to that for the hitherto-used standard dose of $550 \mathrm{MBq}$ and, subsequently, even further than the current recommendations for planar nuclear angiography in accordance with ALARA principles. Secondary benefits include reduced costs in terms of the tracer and technetium; encountering shortages of technetium; the possibility of identifying a paravenous injection on the fly; and, potentially, an increased uniformity of test results across patient age, sex, height, and weight as well as changes, particularly in the latter. 
Author Contributions: M.N.H., C.H., B.K. and B.Z. contributed to the study conception and design, material preparation, data collection, and analysis. The first draft of the manuscript was written by M.N.H., C.H., B.K. and B.Z., and M.N.H., C.H., B.K. and B.Z. commented on previous versions of the manuscript. All authors have read and agreed to the published version of the manuscript.

Funding: This research received no external funding.

Institutional Review Board Statement: The study was conducted according to the guidelines of the Declaration of Helsinki and approved by the Hospital Management of Herlev-Gentofte Hospital (WorkZone number: 20076870, date of approval 26 February 2021).

Informed Consent Statement: Patient consent was waived because all data were collected for quality control assessment approved by the hospital management. The purpose of the quality control was to ensure that the implementation of a personalised dosage did not alter the quality of the studies made and was evaluated as the ease of analysing test results beyond a pre-set limit and a lower dosage limit in accordance with international recommendations. All patient data were anonymised, and no patient underwent examinations that were not part of their routine assessments. Therefore, written informed consent was redundant.

Data Availability Statement: All the data are available in anonymised form from the corresponding author.

Conflicts of Interest: The authors declare no conflict of interest.

\section{References}

1. Carver, J.R.; Shapiro, C.L.; Ng, A.; Jacobs, L.; Schwartz, C.; Virgo, K.S.; Hagerty, K.L.; Somerfield, M.R.; Vaughn, D.J. American society of clinical oncology clinical evidence review on the ongoing care of adult cancer survivors: Cardiac and pulmonary late effects. J. Clin. Oncol. 2007, 25, 3991-4008. [CrossRef]

2. Curigliano, G.; Cardinale, D.; Suter, T.; Plataniotis, G.; De Azambuja, E.; Sandri, M.T.; Criscitiello, C.; Goldhirsch, A.; Cipolla, C.; Roila, F. Cardiovascular toxicity induced by chemotherapy, targeted agents and radiotherapy: ESMO clinical practice guidelines. Ann. Oncol. 2012, 23 (Suppl. 7), 155-166. [CrossRef] [PubMed]

3. Yeh, E.T.; Bickford, C.L. Cardiovascular complications of cancer therapy: Incidence, pathogenesis, diagnosis, and management. J. Am. Coll Cardiol. 2009, 53, 2231-2247. [CrossRef]

4. Zamorano, J.L.; Lancellotti, P.; Rodriguez Muñoz, D.; Aboyans, V.; Asteggiano, R.; Galderisi, M.; Habib, G.; Lenihan, D.J.; Lip, G.Y.H.; Lyon, A.R.; et al. 2016 ESC Position Paper on cancer treatments and cardiovascular toxicity developed under the auspices of the ESC Committee for Practice Guidelines. Eur. Heart J. 2016, 37, 2768-2801. [CrossRef] [PubMed]

5. Plana, J.C.; Galderisi, M.; Barac, A.; Ewer, M.S.; Ky, B.; Scherrer-Crosbie, M.; Ganame, J.; Sebag, I.A.; Agler, D.A.; Badano, L.; et al. Expert consensus for multimodality imaging evaluation of adult patients during and after cancer therapy: A report from the American Society of Echocardiography and the European Association of Cardiovascular Imaging. Eur. Heart J. Cardiovasc. Imaging 2014, 15, 1063-1093. [CrossRef]

6. Foley, T.A.; Mankad, S.V.; Anavekar, N.S.; Bonnichsen, C.R.; Morris, M.F.; Morris, T.D.; Araoz, P. Measuring left ventricular ejection fraction-techniques and potential pitfalls. Eur. Cardiol. 2012, 8, 108-114. [CrossRef]

7. Hesse, B.; Lindhardt, T.B.; Acampa, W.; Anagnostopoulos, C.; Ballinger, J.; Bax, J.J.; Edenbrandt, L.; Flotats, A.; Germano, G.; Stopar, T.G.; et al. EANM/ESC guidelines for radionuclide imaging of cardiac function. Eur. J. Nucl. Med. Mol. Imaging 2008, 35, 857. [CrossRef] [PubMed]

8. Jensen, M.M.; Schmidt, U.; Huang, C.; Zerahn, B. Gated tomographic radionuclide angiography using cadmium-zinc-telluride detector gamma camera; Comparison to traditional gamma cameras. J. Nucl. Cardiol. 2014, 21, 384-396. [CrossRef]

9. Duvall, W.L.; Guma-Demers, K.A.; George, T.; Henzlova, M.J. Radiation reduction and faster acquisition times with SPECT gated blood pool scans using a high-efficiency cardiac SPECT camera. J. Nucl. Cardiol. 2016, 23, 1128-1138. [CrossRef] [PubMed]

10. Jensen, M.M.; Haase, C.; Zerahn, B. Interstudy repeatability of left and right ventricular volume estimations by serial-gated tomographic radionuclide angiographies using a cadmium-zinc-telluride detector gamma camera. Clin. Physiol. Funct. Imaging 2015, 35, 418-424. [CrossRef]

11. Van Dijk, J.D.; Jager, P.L.; Ottervanger, J.P.; Slump, C.H.; de Boer, J.; Oostdijk, A.H.J.; Van Dalen, J.A. Minimizing patient-specific tracer dose in myocardial perfusion imaging using CZT SPECT. J. Nucl. Med. Technol. 2015, 43, 36-40. [CrossRef]

12. Van Dijk, J.D.; Jager, P.L.; Mouden, M.; Slump, C.H.; Ottervanger, J.P.; de Boer, J.; Oostdijk, A.H.J.; van Dalen, J.A. Development and validation of a patient-tailored dose regime in myocardial perfusion imaging using CZT-SPECT. J. Nucl. Cardiol. 2014, 21, 1158-1167. [CrossRef] [PubMed]

13. Acampa, W.; Buechel, R.R.; Gimelli, A. Low dose in nuclear cardiology: State of the art in the era of new cadmium-zinc-telluride cameras. Eur. Heart J. Cardiovasc. Imaging 2016, 17, 591-595. [CrossRef] [PubMed]

14. Gimelli, A.; Achenbach, S.; Buechel, R.R.; Edvardsen, T.; Francone, M.; Gaemperli, O.; Hacker, M.; Hyafil, F.; Kaufmann, P.A.; Lancellotti, P.; et al. Strategies for radiation dose reduction in nuclear cardiology and cardiac computed tomography imaging: 
A report from the European Association of Cardiovascular Imaging (EACVI), the Cardiovascular Committee of European Association of Nuclear Medicine (EANM), and the European Society of Cardiovascular Radiology (ESCR). Eur. Heart J. 2018, 39, 286-296.

15. Duvall, W.L.; Croft, L.B.; Godiwala, T.; Ginsberg, E.; George, T.; Henzlova, M.J. Reduced isotope dose with rapid SPECT MPI imaging: Initial experience with a CZT SPECT camera. J. Nucl. Cardiol. 2010, 17, 1009-1014. [CrossRef]

16. van Dijk, J.D.; Jager, P.L.; Ottervanger, J.P.; de Boer, J.; Oostdijk, A.H.J.; Engbers, E.M.; Slump, C.H.; Knollema, S.; Van Dalen, J.A. Development and validation of a patient-tailored dose regime in myocardial perfusion imaging using conventional SPECT. $J$. Nucl. Cardiol. 2016, 23, 134-142. [CrossRef] [PubMed]

17. Ramon, A.J.; Yang, Y.; Pretorius, P.H.; Johnson, K.L.; King, M.A.; Wernick, M.N. Personalized Models for Injected Activity Levels in SPECT Myocardial Perfusion Imaging. IEEE Trans. Med. Imaging 2019, 176, 139-148. [CrossRef]

18. Glynn, R.B.; Narveson, L.G.; Hung, J.C.; Gibbons, R.J. Adjustment to radionuclide angiogram dose based upon patient's physical parameters. J. Nucl. Med. Technol. 1994, 22, 17-20.

19. Rydberg, J.; Andersen, J.; Haarmark, C.; Zerahn, B. The influence of anthropometric and basic circulatory variables on count rate in cadmium-zinc-telluride SPECT gated radionuclide angiography. J. Nucl. Cardiol. 2018, 26, 1974-1980. [CrossRef] [PubMed]

20. Huang, C.; Ismail, A.; Kristensen, B.; Zerahn, B. Evaluation of individualized dosage planning when performing Cadmium-ZincTelluride SPECT camera gated tomographic radionuclide angiography (abstract). In Proceedings of the Annual Congress of the European Association of Nuclear Medicine, Düsseldorf, Germany, 13-17 October 2018; p. S734.

21. Van Dijk, J.D. Dose-optimization in nuclear cardiac imaging, time for the next step? (editorial). J. Nucl. Cardiol. 2019, 26, 1981-1983. [CrossRef] [PubMed]

22. Danish Department of Health. Referenceniveauer-Nuklearmedicinske Undersøgelser. 2016. Available online: https: / / www.sst.dk/- / media/Udgivelser/2016/Vejledning---Referenceniveauer-Nuklearmedicinske-Unders\%C3\%B8gelser.ashx? la=da\&hash=F86A8F4D1841698CCC642048CCA4FF84979103D3 (accessed on 3 December 2021).

23. Ostensen, H.; Ingolfsdottir, G.; Munro, L.; Diagrammes, A.L.; Conway, M.; Walters, F. Basics of Radiation Protection for Everyday Use. How to achieve ALARA: Working Tips and Guidelines. 2004. 83p. Available online: http://www.who.int/iris/handle/10 665/42973\#sthash.IoEW70Vr.dpuf (accessed on 3 December 2021).

24. Nguyen, T.Q.; Rydberg, J.; Zerahn, B.; Kristensen, B. The effect of dose reduction on left ventricular volumes and ejection fraction assessed by cadmium-zinc-telluride SPECT gamma camera gated tomographic radionuclide angiography (abstract). Eur. J. Nucl. Med. Mol. Imaging 2016, 43, S170.

25. Hansen, M.N.; Kristensen, B.; Haarmark, C.; Zerahn, B. The effect of tissue attenuation on count rate in Cadmium-Zinc-Telluride SPECT gated radionuclide angiography (abstract). In Proceedings of the Abstracts for All Posters, 63rd Nordic Congress of Radiology \& 24th Nordic Congress of Radiography, Copenhagen, Denmark, 22-24 May 2019; pp. 52-53. 